\title{
РОЛЬ И ЗНАЧЕНИЕ ПРИНЦИПОВ ПРАВА В СУДЕБНОЙ ПРАКТИКЕ
}

(c) 2021 Стуликова Надежда Викторовна

аспирант

Самарский государственный экономический университет, Россия, Самара

В статье раскрывается сущность принципов права в их широком понимании, приводятся их основные характеристики, отражающие выражение данной категории в рамках судебного процесса. Анализируются ключевые особенности классификации принципов на судоустройственные и судопроизводственные. Раскрываются особенности судебной практики в области использования принципов процессуального и материального права, их взаимосвязь между собой. Выявляются особенности и проблемы, связанные с их применением судами. Практическая реализация принципов права классифицируется по основанию их функционального назначения на: процессуальную связанную с определением возможности рассмотрения определенного вопроса или спора в целом судом, и прикладную - связанную с предоставлением широких полномочий суду по устранению недостатков законодательного регулирования правоотношений посредством прямого следованию принципам права.

Ключевые слова: гражданский и арбитражный процесс, принципы права, судебная защита, судебная практика.

Принципы права, являясь исходными, основополагающими постулатами юридической науки, формируются на основе научных и практических требованиях правовой действительности. Данная категория в науке определяется как основные и наиболее существенные идеи права, определяющие направление правового регулирования посредством конкретизации его сущности. В принципах права раскрывается социальное назначение регулирования в системе ведущих, основополагающих идей, его ценностный потенциал*.

В постиндустриальный период человеческой цивилизации в развитых правопорядках право (как на национальном, так и на международном уровнях) пронизано ценностями справедливости, равенства, гуманизма и мн. др.**; которые в свою очередь посредством эволюционных процессов трансформировались в принципы права.

При этом, вне зависимости от того, находят ли принципы свое отражение в нормах права, ими обеспечивается реализация гарантированных законодательством прав на правовое регулирование общественных отношений в соответствии с существующими потребностями общества. Закрепление в юридической науке категории принципов права отражает ее объективную необходимость в нахождении и за- креплении предписаний, которые бы являлись основополагающими направлениями развития правовой науки, посредством закрепления соответствующих принципам норм права. Нормы-принципы в таком случае служат двойному назначению: отождествлению законодателем надлежащего правового регулирования и направлению субъектов на правомерное поведение для обеспечения стабильности и предсказуемости гражданского оборота.

Тем не менее, необходимо отметить, что в процессе нормотворчества могут допускаться ошибки, в связи с чем вероятность применения нормы, прямо указывающая действовать определенным образом, однако не соответствующая в полной мере принципам права, существенно снижается. Невозможность использования сомнительной с точки зрения правоприменителя нормы, порожденной ошибкой законодателя, создает объективную необходимость в свободе применения основных начал законодательства судом напрямую, восполняя пробелы законодательства. При этом следует отметить, что основными определяющими факторами в такой ситуации являются правовое сознание, профессиональная правовая культура и совесть судьи.

Установленная в правовой системе общества совокупность основополагающих начал

\footnotetext{
* Ланг П.П.Аксиологические начала права // Российская юстиция. - 2018. - № 8.- С. 2-4.

** Ланг П. П.Ценностное измерение правового регулирования // Вопросы экономики и права. - 2018. - № 121.C. 20-24.
} 
обеспечивается соблюдением их социальнополитическими институтами, в первую очередь, государственными органами, непосредственно их нормативно закрепляющих. При этом нормативность принципов - закрепление соответствующих постулатов в нормативных актах, является гарантией, определяющей общеобязательность их применения, несмотря на то, что генезис принципов не связан напрямую с данной характеристикой.

Теоретические начала принципов права является достаточно основательно изученной категорией в юриспруденции, относится к наиболее традиционным, определяющих теоретическую обоснованность и практическую значимость каждого принципа права, их сравнительные характеристики, а также особенности принципов и из проявления в различных отраслях права. Однако, дискуссионная ценность указанного вопроса не утратила своей значимости ввиду непрекращающейся деятельности по совершенствованию законодательства, а вместе с ней формирования правоприменительной практики*.

Безусловно, существо принципов обеспечивается в том числе благодаря их общепризнанности, естественности для общества, а также в связи с тем, что социальное устройство правовой действительности нацелено на наиболее эффективное взаимодействие ее отдельных частей, что обеспечивает значительную взаимосвязь отраслей права на текущем этапе развития правовой науки, в том числе, общностью основополагающих начал. Практическая деятельность правоприменителей, исследователей имеет своей целью в большей степени изучение и максимально эффективное использование инструментальных вопросов, применении ординарных норм процессуального и материального права, их толковании. Одновременно с этим применение принципов в ходе практической деятельности составляет существенную часть деятельности правоприменителей, в первую очередь, в области судебных споров.

Категория принципов, являясь общеправовой категорией, изучению которой посвящены существенные объемы научных трудов, в связи с чем в рамках настоящего исследования следует ограничить рамками практической стороны гражданского судебного процесса, как регулируемой процессуальным законодательством деятельности суда, а также иных лиц, ставящее своей целью на рассмотрение и разрешение спора в области гражданского законодательства по существу.

Система принципов права представляет собой сложную систему, в которую входят полиструктурные образования**, определяющие место того или иного элемента правовой системы общества, соответствующие его положению взаимоотношения с другими разделами правовой науки, отраслями права. В частности, одним из наиболее значимых элементов правовой действительности является судебная власть, ее организация и правила осуществления стоящих перед ней целей, основополагающие начала которых выражаются в виде судоустройственных (организационных) и судопроизводственных (функциональных) принципов процессуального права.

Безусловно, такое разграничение является условным и носит скорее методологическое значение, поскольку в каждом принципе выражены и организационные и функциональные элементы. Тем не менее, такое разграничение в рамках практической судебной деятельности носит весьма прикладное значение, поскольку влияет непосредственно на существо отправления правосудия. Условное разграничение непосредственно влияет на установление возможности рассмотрения по существу спорных правоотношений, поскольку соблюдение судоустройственных принципов влияет на возможность начала судебной деятельности, в то время как судопроизводственными принципами обеспечивается сам процесс ее проведения.

В силу своего исключительного характера судоустройственные принципы достаточно редко отражаются в судебных актах, поскольку правоотношения, которые являются предметом судебного разбирательства, не связаны напрямую с судебной системой, не посягают на ее организационные начала. Тем не менее, вопрос о их соблюдении судами является непременным условием рассмотрения дела по существу.

В то же время функциональные принципы (принципы судопроизводства) определяют как общие, универсальные правила осуществления

* Ланг П.П.Ценность и экзистенция принципов права // Евразийский юридический журнал. - 2021. - № 6(157). C. 84-87.

** Карташов В.Н. Принципы права: понятие, структуры, функции // Юридическая техника. - 2020. - № 14. URL: https://cyberleninka.ru/article/n/printsipy-prava-ponyatie-struktury-funktsii (дата обращения: 16.07.2021). 
судебной власти (право граждан на судебную защиту, язык судопроизводства, состязательность и равенство сторон в процессе и т.д.), а также особенности, присущие определенным видам судопроизводства. Значение принципов судопроизводства состоит в обеспечении лицам, участвующим в деле, гарантий принятия законного и обоснованного решения по делу, изучении судом всех аспектов спорного правоотношения, предоставлении в равной степени возможности пользоваться процессуальными инструментами судебной защиты.

Следует отметить, что судебное разбирательство строится на основе сочетания материального и процессуального права таким образом, при котором разрешаются возникающие в процессе хозяйственной деятельности спорные правоотношения по существу (сфера материального права) посредством особой формы, относящейся к процессуальному праву. Необходимо отметить, что в науке достаточно критически оценивают возможность использования философской парной конструкции «содержание форма» применительно к оценке соотношения и взаимосвязи материального и процессуального права*, однако, именно в процессе судопроизводства эта конструкция выражена в наибольшей степени. Процесс собирания доказательств, представления их лицами, участвующими в деле, представление пояснений по материальным основаниям носит процессуальный характер, в то время как вынесение судебного решения является процессуальной формой закрепления материальных прав тяжущихся лиц.

Основной формирования гражданского и арбитражного процессуального права является материальная отрасль гражданского права. Поэтому специфика регулируемых ею общественных отношений становится фактором, определяющим использование соответствующих принципов в практической деятельности.

Принципы гражданского права, занимающие основное место в гражданской правоприменительной практике, являются более антропоцентричными по своему существу, в отличие от принципов процессуального законодательства, поскольку последнее в меньшей степени тяготеет к интересам отдельного лица, уста- навливая наравне с ценностями защиты прав конкретного субъекта правоотношений защиту общественного интереса, и имеет своей целью достижение баланса между ними.

Нахождение разумного баланса при полной противоположности интересов участников гражданских правоотношений относится к главным проблемам цивилистической науки. При этом основным принципом, призванным сдерживать проявление личного эгоизма там, где этот эгоизм начинает выступать препятствием для жизни социума** выступает принцип диспозитивности. В ходе производства в суде первой инстанции влияние данного принципа прослеживается до возбуждения процесса, поскольку определяются основания предъявления требований: инициативность лица, условия и порядок заявления, основания отказа в возбуждении дела; привлечения или вступления в дело соответчиков и третьих лиц, соединения и разъединения нескольких исковых требований, принятия мер по обеспечению иска; при рассмотрении дела в судебном заседании определяются условия и порядок замены ненадлежащих сторон (возможные изменения в иске), а также отказа истца от иска и признания иска ответчиком.

В полном соответствии с принципом диспозитивности находится и другое важное положение гражданского процесса: суды не могут по собственной инициативе рассматривать незаявленное требование. В судебной практике последних лет малейшие отступления от этого правила расцениваются как существенные нарушения принципа диспозитивности, являются безусловным поводом к отмене принятого по делу решения.

Нарушение принципов судопроизводства в рамках гражданского процесса является серьёзным нарушением процессуальных норм, на которое часто обращает внимание Верховный Суд РФ, пересматривающий судебные решения нижестоящих судов. Так, Определением Судебной коллегии по гражданским делам Верховного Суда РФ от 09.09.2008 № 39-В08-156 были отменены решения нижестоящих судов, а дело направлено на новое рассмотрение по причине того, что суд вышел за пределы исковых требований и вынес решение по вопросу, который

\footnotetext{
* Грось Л.А. Влияние норм материального права на гражданское процессуальное право: Научно-практические проблемы: автореф. дис. ... д-ра юрид. наук. М., 1999. С. 4.

** Егоров А.В.Принцип добросовестности в Гражданском кодексе РФ: первые шаги реформы // Legal insight. 2013. № 2(18). C. 9.
} 
не был заявлен при рассмотрении дела судом ни истцом, ни ответчиком, тем самым нарушив принцип диспозитивности гражданского судопроизводства, вытекающий из положений ст. 39 и ч. 3 ст. 196 ГПК РФ*.

Также предметом рассмотрения высшей судебной инстанции являются иные принципы судопроизводства, действующих непосредственно в процессе судебного разбирательства, в частности, состязательности, которая являет собой построение процесса на основе противоположности интересов сторон при минимизации участия суда, при этом устанавливая определенные пределы, в рамках которых должны быть совершены процессуальные действия**. Однако, правоприменительная практика принципов, которые связаны с непосредственным процессом судебного разбирательства, его порядка, чаще находят свое выражение в обзорах судебной практики, а не соответствующих постановлениях. В большей степени данное обстоятельство связано с определением судами обзоров как рекомендательными предписаниями, сильной зависимостью от конкретных обстоятельств дела, применение которой в ходе ординарной судебной деятельности в каждом случае представляется затруднительным и не соответствующим целевому предназначению таких разъяснений. Так в одном из определений*** Верховный Суд РФ указал на необходимость доказывания обстоятельств, на которые ссылаются кредитор по денежным обязательствам, заявивший свои требования в деле о банкротстве, как на основание своих требований или возражений, обоснованность которых определяется на основе принципа состязательности.

Использование принципов диспозитивно- сти, устанавливающего возможность рассмотрения спора, и состязательности, определяющего его ход, в этой части является характерным примером процессуальной функции принципов права в судебной практике, поскольку определяют обстоятельства судебного разбирательства, связанных с гарантированным правом на судебную защитуж***, недопустимостью замещения частноправовых интересов публичными, на которые должны быть ориентирована вся судебная деятельность при рассмотрении спора.

При этом, следует отметить также иную функцию, которую выполняют принципы права в практической судебной деятельности - обеспечение возможности лицам, участвующим в деле, возможности представлять доказательства, строить позицию на основании принципов права, основных начал законодательства, а также суду - формировать мотивировочную базу справедливых, соответствующих объективным обстоятельствам, решений суда по вопросам, как не урегулированным напрямую нормами закона, так и имеющих недостатки, ранее обозначенные в статье. Стоит отметить, что не ограничиваясь практической деятельностью, принципы права имеют и другие функции, которые, однако не относятся к предмету исследования, поскольку затрагивают, в большей степени, области законотворчества, чем правоприменительную деятельность.

Анализ судебной практики позволяет говорить о том, что наиболее часто при разрешении вопроса по существу суды руководствуются принципами справедливости, добросовестности и равенства сторон ${ }^{* * * * * * . ~ Р а с п р о с т р а н е н н о с т ь ~}$ указанных основополагающих начал связана, в первую очередь, с невозможностью закрепле-

\footnotetext{
* Определение Верховного Суда РФ от 09.09.2008 № 39-В08-1 // Бюллетень Верховного Суда РФ, № 3, 2009.

** Кашкарова И.Н. Анализ практики применения арбитражными судами положений ч. 2 ст. 9 АПК РФ о процессуальных рисках участников состязательного процесса. [Электронный ресурс] // Сайт СПбГУ. http://pravoprim. spbu.ru (дата обращения: 09.07.2021 г.)

*** «Обзор судебной практики Верховного Суда Российской Федерации N 4 (2018)» (утв. Президиумом Верховного Суда РФ 26.12.2018) // Определение Верховного Суда Российской Федерации N 310-ЭС17-20671 // Сайт Верховного Суда Российской Федерации [Электронный ресурс] https://www.vsrf.ru/ (дата обращения: 09.07.2021 г.) **** Ланг П.П. Сущность и принципы доказывания в арбитражном судопроизводстве // Юридическая наука.2018. - № 4.- С. 87-92.

***** См.: Постановление Арбитражного суда Поволжского округа от 03.09.2021 № Ф06-9226/2021 по делу № A72-5136/2020 // // Документ опубликован в порядке п.5 ст.15 АПК РФ в форме электронного документа // Сайт Мой Арбитр [Электронный ресурс]. - Электр. дан.- Мой арбитр. URL: http://my.arbitr.ru; Постановление Арбитражного суда Поволжского округа от 02.09.2021 № Ф06-3035/2021 по делу № А65-21073/2019 // // Документ опубликован в порядке п.5 ст.15 АПК РФ в форме электронного документа // Сайт Мой Арбитр [Электронный ресурс].- Электр. дан.-Мой арбитр. URL: http://my.arbitr.ru
} 
ния в нормах права оценочных категорий, однако требует определенной степени сформированности позиций по применению того или иного принципа в судебной практике.

В частности, принцип справедливости, напрямую закрепленный в ст.1 Гражданского кодекса РФ, и не установленный прямо в нормах гражданского процессуального и арбитражного процессуального права отражает наличие противоречий в области материального и процессуального права, основное предназначение которых в наиболее широком смысле состоит в регулировании гражданских правоотношений. В процессуальных кодексах принцип справедливости возможно выявить при комплексном изучении задач арбитражного судопроизводства, состоящих в том числе в справедливом судебном разбирательстве, а также в гражданском процессуальном законодательстве, которое ставит его в зависимость от соблюдения принципов состязательности и равноправия сторон.

Отсутствие напрямую обозначенного принципа в соответствующих процессуальных кодексах, однако, не следует относить к недочетам действующего законодательства, хотя в нормах Кодекса административного судопроизводства РФ напрямую закреплен принцип справедливости при рассмотрении и разрешении административных дел. Такой неоднозначный подход к закреплению принципа справедливости связан, в первую очередь, с достаточно сложной взаимосвязью с принципом законности, соотношение которых в процессе правоприменения зачастую имеет свои противоречия.

Конституционный Суд РФ в одном из своих постановлений указал, что правосудие, может признаваться таковым только при условии, если оно отвечает требованиям справедливости, обеспечивая эффективное восстановление в правах. Потому устанавливая порядок его отправления, федеральный законодатель, обязан предусмотреть процедуру, которой гарантировал бы вы- несение правосудных, а потому законных, обоснованных и справедливых судебных решений. Государство обязано обеспечить осуществление права на справедливую, компетентную и действенную судебную защиту*.

В частности, вопрос об определении размера подлежащих взысканию неустойки, убытков напрямую связан с применением судом принципа справедливости. Так, в постановлении Пленума Верховного Суда Российской Федерации от 24.03.2016 N 7 «О применении судами некоторых положений Гражданского кодекса Российской Федерации об ответственности за нарушение обязательств» размер судебной неустойки определяется судом на основе принципов справедливости, соразмерности и недопустимости извлечения должником выгоды из незаконного или недобросовестного поведения.

Согласно разъяснению, содержащемуся в п. 12 постановления Пленума Верховного Суда Российской Федерации от 23 июня 2015 г. № 25 «О применении судами некоторых положений раздела I части первой Гражданского кодекса Российской Федерации», размер подлежащих возмещению убытков должен быть установлен с разумной степенью достоверности. По смыслу п. 1 ст. 15 ГК РФ в удовлетворении требования о возмещении убытков не может быть отказано только на том основании, что их точный размер невозможно установить. В этом случае размер подлежащих возмещению убытков определяется судом с учетом всех обстоятельств дела, исходя из принципов справедливости и соразмерности ответственности допущенному нарушению*** В дальнейшем положения не только о возможности, но даже необходимости применения указанных принципов воспринимается нижестоящими судебными инстанциями ***. Изложенное свидетельствует о достаточно широком применении принципов права в прикладном его назначении.

Из этого следует отметить, что возможность

\footnotetext{
* Постановление Конституционного Суда РФ от 02.07.2013 № 16-П «По делу о проверке конституционности положений части первой статьи 237 Уголовно-процессуального кодекса Российской Федерации в связи с жалобой гражданина Республики Узбекистан Б. Т. Гадаева и запросом Курганского областного суда» // СЗ РФ. 2013 . № 28. Ст. 3881.

** «Обзор судебной практики Верховного Суда Российской Федерации N 4 (2018)» (утв. Президиумом Верховного Суда РФ 26.12.2018) // Определение Верховного Суда РФ № 18-КГ17-257 // Сайт Верховного Суда Российской Федерации [Электронный ресурс] https://www.vsrf.ru/ (дата обращения: 09.07.2021 г.)

*** Постановление Одиннадцатого арбитражного апелляционного суда от 01.04.2021 по делу Дело № А6515548/2019 // Документ опубликован в порядке п.5 ст.15 АПК РФ в форме электронного документа // Сайт Мой Арбитр [Электронный ресурс].-Электр. дан.- Мой арбитр. URL: http://my.arbitr.ru
} 
применения судебными инстанциями принципов права напрямую становится предметом рассмотрения практики в высшей судебной инстанции. Закрепление возможности применения принципа права при рассмотрении тех или иных категорий споров, вопросов, подлежащих установлению и оценке в результате их разрешения, имеет своей целью индивидуализировать каждое конкретное судебное разбирательство, предоставив судам первой инстанции возможность оценивать доводы лиц, участвующих в деле, с позиций основных начал законодательства.
Из изложенного можно сделать вывод о том, что значение принципов в практической деятельности в судопроизводстве имеет двойственный характер, выраженный в обстоятельствах, связанных с предоставлениям лицам, участвующим в деле гарантированных конституционными нормами прав, а также с предоставлением судебным органам, лицам, участвующим в деле, широкого инструментария мотивирования позиции по делу. Таким образом, возможно выделить процессуальную и прикладную функции принципов права в судебной практике, определяющие их роль и значение в сфере судебной деятельности.

\section{Библиографический список}

1. росьЛ. А. Влияние норм материальногоправа на гражданскоепроцессуальное право:Научно-практические проблемы: автореф. дис. ... д-ра юрид. наук. М., 1999. С. 4.

2. Егоров А. В. Принцип добросовестности в Гражданском кодексе РФ: первые шаги реформы // Legal insight. 2013. - № 2(18). - С. 9.

3. Карташов В.Н. Принципы права: понятие, структуры, функции // Юридическая техника. 2020. № 14. URL: https://cyberleninka.ru/article/n/printsipy-prava-ponyatie-struktury-funktsii (дата обращения: 16.07.2021).

4. Кашкарова И.Н. Анализ практики применения арбитражными судами положений ч. 2 ст. 9 АПК РФ о процессуальных рисках участников состязательного процесса. [Электронный ресурс] // Сайт СПбГУ. http:// pravoprim.spbu.ru (дата обращения: 09.07.2021 г.).

5. Ланг П. П. Аксиологические начала права // Российская юстиция. - 2018. - № 8.- С. 2-4.

6. Ланг П. П. Сущность и принципы доказывания в арбитражном судопроизводстве // Юридическая наука.2018. - № 4.- С. 87-92.

7. Ланг П.П. Ценностное измерение правового регулирования // Вопросы экономики и права.- 2018.№ $121 .-$ С. 20-24.

8. Ланг П.П. Ценность и экзистенция принципов права // Евразийский юридический журнал.- 2021.№ 6(157). - С. 84-87. 